\title{
Validation of a skin and coat scoring protocol in dogs
}

\author{
Validatie van een huid- en vachtscoreprotocol bij honden
}

\author{
${ }^{1}$ N. Devriendt, ${ }^{1}$ T.C.N. Rodrigues, ${ }^{1}$ S. Vandenabeele, ${ }^{1}$ S. Favril, ${ }^{1}$ A. Biscop, ${ }^{1}$ S. Marynissen, \\ ${ }^{2}$ B.J.G. Broeckx, ${ }^{1}$ I. Hofstra, ${ }^{1}$ F. Mortier, ${ }^{3}$ E. de Bakker, ${ }^{1}$ L. Vlerick, ${ }^{1}$ H. de Rooster
}

\author{
${ }^{1}$ Small Animal Department, Faculty of Veterinary Medicine, Ghent University, \\ Salisburylaan 133, 9820 Merelbeke, Belgium \\ ${ }^{2}$ Department of Nutrition, Genetics and Ethology, Faculty of Veterinary Medicine, Ghent University, \\ Heidestraat 19, 9820 Merelbeke, Belgium \\ ${ }^{3}$ Department of Medical Imaging of Domestic Animals and Small Animal Orthopedics, \\ Faculty of Veterinary Medicine, Ghent University, Salisburylaan 133, 9820 Merelbeke, Belgium
}

nausikaa.devriendt@ugent.be

\section{BSTRACT}

Skin and coat scores have been used to assess changes in skin and coat quality in dogs. The aim of this study was to evaluate a skin and coat protocol in dogs of different coat types. Skin and coat of long-haired, short-haired and wire-haired dogs were scored for alopecia, glossiness, greasiness, softness, scaliness and overall skin and coat quality by ten observers. Intraobserver and interobserver agreement was assessed using kappa values. Thirty-six client-owned dogs were included in the study. The overall intraobserver agreement was moderate when assessing greasiness and glossiness and substantial when assessing alopecia, softness, scaliness and overall skin and coat quality. The overall interobserver agreement was only slight to fair for all features assessed. In conclusion, the proposed skin and coat scoring protocol assesses different aspects of the skin and coat quality in dogs and is easy and non-invasive. Scoring skin and coat quality over time is only reliable if performed by the same person.

\section{SAMENVATTING}

De huid- en vachtkwaliteit van honden kan worden beoordeeld met behulp van huid- en vachtscores. Het doel van deze studie was om een huid- en vachtscoreprotocol te evalueren bij honden met een verschillende vachttype. De huid en vacht van langharige, kortharige en ruwharige honden werden beoordeeld op alopecie, glans, vettigheid, zachtheid, schilfering en algehele huid- en vachtkwaliteit door tien personen. Overeenkomsten van waarden binnen en tussen de verschillende personen werden bepaald met behulp van kappawaarden. Er werden 36 eigenaarshonden ingesloten. De algehele overeenkomst binnen personen was matig voor het bepalen van vettigheid en glans en aanzienlijk bij het beoordelen van alopecie, zachtheid, schilfering en algehele huid- en vachtkwaliteit. De algehele overeenkomst tussen personen was slechts gering tot redelijk voor alle kenmerken die werden beoordeeld. Concluderend kan gesteld worden dat het voorgestelde huid- en vachtscoreprotocol waarmee verschillende aspecten van de huid- en vachtkwaliteit kunnen worden beoordeeld bij de hond gemakkelijk uitvoerbaar en niet invasief is. Het beoordelen van de huid- en vachtkwaliteit over een langere termijn is alleen betrouwbaar als het steeds door dezelfde persoon wordt uitgevoerd.

\section{INTRODUCTION}

Skin is the largest metabolically active organ reflecting nutritional and hormonal imbalances (Watson, 1998; Frank, 2006). Healthy dog skin contains a large variety of microbiota, which can be affected by several diseases(Weese, 2013; Cuscó et al., 2017). Skin scoring can be used to assess general health and welfare on the one hand and can help to assess reaction to therapy by repeated scoring over time on the other hand (Berg 
et al., 2009; Marufu et al., 2011; Plant et al., 2012; Olivry et al., 2014). Several studies have included an ordinal skin and coat score to assess changes in skin and coat quality in dogs when given different types of food and/or supplements (Marsh et al., 2000; Rees et al., 2001; Kirby et al., 2009). In a study by Rees et al. (2001), six evaluators (two nutritionists, two dermatologists and two laboratory technicians) gave one score to both the skin and coat condition in 18 cross breed dogs. The skin condition scores of two evaluators did not correlate with the scores of the remaining four, one of which also had hair coat condition scores that did not correlate with the other five evaluators. In another study by Marsh et al. (2000), five trained evaluators scored glossiness, softness, greasiness and scaliness in 32 black Labrador retrievers and in a study by Kirby et al. (2009), seven trained evaluators (veterinarians and graduated students) scored glossiness, softness, greasiness, scaliness and overall coat quality in nine beagles and 15 hound type cross breed dogs. In the last two studies, scores from 1 to 5 had to be given, with score 1 representing poor and score 5 representing excellent condition for the scored feature (Marsh et al., 2000; Kirby et al., 2009).

The aim of the present study was to assess the influence of different coat types on skin and coat scoring in dogs with a wide variety of skin and coat conditions. As healthy dogs with different coat types will be scored differently (e.g. wire-haired dogs have naturally more coarse hair than long-haired and short-haired dogs), it is important to assess skin and coat scoring protocols in dogs with different coat types.

\section{MATERIALS AND METHODS}

The study was approved by the local ethical committee (EC 2018-89). Long-, short- and wire-haired dogs, hospitalized because of different diseases, were enrolled. Each morning during the study period, all hospitalized dogs were assessed by the same person (ND). Dogs were eligible for inclusion when they were likely to stay hospitalized for the remainder of the day. Dogs with hair clipped on the back, dogs with obvious ectoparasites, and dogs, for which gloves needed to be worn during manipulation, were excluded. If less than five dogs were included on one day, they were only scored once. Otherwise, dogs were scored twice, to allow for intraobserver agreement. Dogs that were likely to stay hospitalized for multiple days were scored once in the beginning and a second time at the end of the hospitalization period, to serve the same purpose. All dogs were randomized, ensuring that the dogs were not scored twice in a row using Randomness \& Integrity Services (True random number generator.www.random.org; accessed in December 2019 and January 2020). Scoring sheets were given to the observers in the order in which the dogs needed to be assessed. A closed, opaque box was provided to drop completed sheets after each assessment. Scoring was performed during daytime in the hospital ward with ample light. Scoring sheets of dogs that were not in the kennel at the moment of the intended scoring were placed in the box without being filled out.

Ten veterinarians performed the scorings: two dermatologists (one ECVD diplomate and one ECVD resident), four practitioners with more than five years of experience, of which two in internal medicine and two in surgery, two practitioners with less than one year experience (interns), and two non-practitioners who followed a $\mathrm{PhD}$ trajectory for more than three years.

None of the observers was familiar with the skin and coat score under evaluation. Prior to the start of the study, a brief explanation was provided on how to score. Skin and coat scoring had to be performed based on the skin and coat on the entire dorsal part of the dog from the neck region to the interscapular region unto the sacrum. Six features were evaluated, all scored from 1 to 5 (Score sheet). Alopecia and glossiness had to be scored on visual assessment, with alopecia ranging from no alopecia (1) to bald (5) and glossiness ranging from highly reflective (1) to dull (5). Greasiness and softness had to be assessed tactilely with greasiness ranging from dry (1) to greasy (5) and softness ranging from very soft (1) to coarse (5). Scaliness had to be assessed between the scapulae, in the thoracolumbar and in the lumbar region by lifting the hairs. The scoring varied between the presence of a minimal amount of scales (1) to a very large amount of scales (5). Finally, the overall skin and coat quality had to be assessed from normal (1) to abnormal (5) for that type of breed.

Statistical analyses were performed using R 3.5.2. For the intraobserver agreement, an agreement score per animal was calculated per observer. These scores were compared between groups with a logistic linear mixed model with group as categorical independent variable and animal as random effect. To evaluate interobserver agreement, only the first score of each

Score sheet: Hair and skin condition (score only dorsal part from neck to sacrum).

\section{Partial alopecia Glossiness \\ Greasiness \\ Softness \\ Scaliness}

Overall coat quality (only visual assessment; 1 no alopecia -5 bald):

(only visual assessment; 1 highly reflective -5 dull):

(tactile assessment; 1 dry -5 greasy):

(tactile assessment; 1 very soft -5 coarse):

(assess on 3 areas (between scapulae, thoracolumbar and lumbar)

by lifting the hair; 1 minimal amount of scale -5 very large amount of scale): .....

(1 normal - 5 abnormal): 
Table 1. Demographic data of included long- and short-haired dogs.

\begin{tabular}{lccc}
\hline & n & $\begin{array}{c}\text { Median age (range) } \\
\text { months }\end{array}$ & $\begin{array}{c}\text { Median body weight (range) } \\
\text { kg }\end{array}$ \\
\hline $\begin{array}{l}\text { Long-haired } \\
\text { Short-haired }\end{array}$ & 19 & $27(4-173)$ & $9.1(1.8-27.3)$ \\
P-value & 15 & $81(14-160)$ & $26.2(5.4-51.5)$ \\
& & 0.319 & $\mathbf{0 . 0 1 2}$ \\
\hline
\end{tabular}

n: number of dogs; P-value in bolt indicates a statistically significant difference

observer picked from the box was used. For each pair of observers, an agreement score per animal was calculated. A logistic mixed model with patient as random effect and group as fixed effect was used to test whether the agreement score differed between groups. For each mixed model, a likelihood ratio test was used to evaluate the significance of the predictor. If significant, a post hoc comparison was performed with Tukey correction. Overall average kappa values and kappa values per group were calculated and interpreted based on a classification system published earlier (Landis and Koch, 1977). To evaluate the effect of long- versus short-haired coat, an agreement score was derived for each animal by determining the percentage of pairs of evaluations (intraobserver) or pairs of observers (interobserver) with the same assessment. Agreement scores, and age and body weight between long- and short-haired dogs were compared using Mann-Whitney U tests. Variables were significant if $\mathrm{P}<0.05$.

\section{RESULTS}

Thirty-six dogs were included: 19 long-haired, 15 short-haired, and two wire-haired dogs (Table 1). Not all observers could evaluate the same number of dogs and/or could evaluate the same dogs twice. The intraobserver agreement was assessed based on 11 to 17 long-haired, 10 to 13 short-haired and one or both wirehaired dogs for each observer. The overall intraobserver agreement was moderate when assessing greasiness and glossiness and substantial when assessing alopecia, softness, scaliness and overall skin and coat quality (Table 2). Dermatologists had a significantly higher agreement for glossiness compared to surgeons (kappa 0.74 versus $0.39, \mathrm{P}=0.029$ ) and for softness compared to interns (kappa 0.71 versus $0.31, \mathrm{P}=0.035$ ).
The interobserver agreement was assessed based on nine long-haired, eight short-haired and both wire-haired dogs. Average kappa values of all observers ranged from $0.01-0.40$ suggesting a slight to fair agreement (Table 2). No significant differences were present between the different groups of observers when observing alopecia, glossiness, greasiness, softness and scaliness. For the overall assessment of skin and coat quality, a significant difference $(\mathrm{P}=$ 0.008 ) was present for surgeons and for interns, with surgeons having a poor agreement (kappa -0.23) and interns having a fair agreement (kappa 0.39).

No significant differences in agreement were found in scores of long- versus short-haired dogs for none of the assessed variables.

\section{DISCUSSION}

The results demonstrated that the interobserver agreement was poor, whereas the intraobserver agreement was moderate to substantial, with dermatologists having a better intraobserver agreement when assessing glossiness and softness compared to surgeons and interns, respectively. The length of hair did not influence any of the agreements. Consequently, the skin and coat scoring protocol can be used in clinical practice, but should always be performed by the same person, ideally a dermatologist, if it is used to assess changes in skin and coat scoring over time.

Apart from the skin and/or coat scorings used in experimental dogs (Marsh et al., 2000; Rees et al., 2001; Kirby et al., 2009), different scoring protocols have been developed for dogs with skin conditions such as atopic dermatitis (Plant et al., 2012; Olivry et al., 2014). More general scoring protocols are available to score skin and coat conditions in cattle and wildlife species, to assess health and welfare in a non-

Table 2. Average kappa values of intraobserver and interobserver agreement for all observers scoring skin and coat conditions in hospitalized dogs with different coat types.

\begin{tabular}{lcc}
\hline & Intraobserver agreement & Interobserver agreement \\
\hline Alopecia & 0.693 & 0.338 \\
Glossiness & 0.539 & 0.051 \\
Greasiness & 0.496 & 0.014 \\
Softness & 0.618 & 0.096 \\
Scaliness & 0.798 & 0.399 \\
Overall skin and coat quality & 0.678 & 0.104 \\
\hline
\end{tabular}


invasive way (Berg et al., 2009; Marufu et al., 2011). A large variation in coat types exists between and within different dog breeds, which is genetically defined (Cadieu et al., 2009). Whereas coarse relatively dull hair is normal in wire-haired dogs, other dog breeds are expected to have a soft and highly reflective coat (Czyz et al., 2012). In contrast to previous studies (Marsh et al., 2000; Rees et al., 2001; Kirby et al., 2009), in this study, a scoring protocol was evaluated to assess different aspects of the skin and coat, without defining features as being 'normal' or 'abnormal' as such in different dog breeds. This is important if the skin and coat scoring protocol is applied to dogs with different coat types.

Although none of the observers had used the skin and coat score prior to the study, the protocol was reported to be easy to use by all observers. Furthermore, none of the included dogs experienced distress by the scorings performed, confirming that it is a noninvasive technique to assess skin and coat quality that can be easily used in the majority of dogs. Nevertheless, the poor interobserver agreement, even between dermatologists, emphasizes the subjectiveness of the score. Consequently, if skin and coat scoring is used over time, dogs should be scored by the same person at the different occasions.

The current study has several limitations. Inclusion was subjected to the availability of hospitalized dogs at the moment of the study. Most dogs underwent diagnostic investigations and therapeutic interventions during their hospitalization and could consequently not always be scored by all observers. Some dogs were scored twice during their hospitalization time with a few days in between, which might have influenced the skin and coat scoring. Nevertheless, only dogs with a predetermined prolonged hospitalization stay, such as dogs boarding for rehabilitation or dogs with a fixed hospitalization period after surgery were included for this purpose. Merely two wire-haired dogs were eligible for inclusion, making it impossible to assess the influence of this coat type on this skin and coat scores. Only the dorsal area of the dogs was scored, as this area has most abundant hair, making it the easiest area to determine coat quality.

In conclusion, the proposed skin and coat scoring protocol assesses different aspects of the skin and coat quality in dogs and is easy and non-invasive. This score can be used to determine skin and coat quality over time, providing that the scoring is always performed by the same person, preferentially a dermatologist.

\section{REFERENCES}

Berg W., Jolly A., Rambeloarivony H., Andrianome V., Rasamimanana H. (2009). A scoring system for coat and tail condition in ringtailed lemurs, Lemur catta. American Journal of Primatology 71, 183-190.

Cadieu E., Neff M.W., Quignon P., Walsh K., Chase K., Parker H.G., Vonholdt B.M., Rhue A., Boyko A., Byers
A., Wong A., Mosher D.S., Elkahloun A.G., Spady T.C., André C., Lark K.G., Cargill M., Bustamante C.D., Wayne, R.K., Ostrander E.A. (2009). Coat variation in the domestic dog is governed by variants in three genes. Science 326, 150-153.

Cuscó A., Belanger J.M., Gershony L., Islas-Trejo A., Levy K., Medrano J.F., Sánchez A., Oberbauer A.M., Francino O. (2017). Individual signatures and environmental factors shape skin microbiota in healthy dogs. Microbiome 5,139 .

Czyz K., Patkowska-Sokola B., Filistowocz A., Janczak M., Bodkowski R. (2012). Analysis of hair coat of Dachshund of longhaired, shorthaired, and wirehaired variety. Bulletin of the Veterinary Institiute in Pulawy 56, 643-647.

Frank L.A. (2006). Comparative dermatology - canine endocrine dermatoses. Clinics in Dermatology 24, 317-325.

Kirby N.A., Hester S.L., Rees C.A., Kennis R.A., Zoran D.L., Bauer J.E. (2009). Skin surface lipids and skin and hair coat condition in dogs fed increased total fat diets containing polyunsaturated fatty acids. Journal of Animal Physiology and Animal Nutrition 93, 505-511.

Landis J.R., Koch G.G. (1977). The measurement of observer agreement for categorical data. Biometrics 33, 159-174.

Marsh K.A., Ruedisueli F.L., Coe S.L., Watson T.G.D. (2000). Effects of zinc and linoleic acid supplementation on the skin and coat quality of dogs receiving a complete and balanced diet. Veterinary Dermatology 11, 277-284.

Marufu M., Qokweni L., Chimonyo M., Dzama K. (2011). Relationships between tick counts and coat characteristics in Nguni and Bonsmara cattle reared on semiarid rangelands in South Africa. Ticks and Tick-Borne Diseases 2, 172-177.

Olivry T., Saridomichelakis M., Nuttall T., Bensignor E., Griffin C.E., Hil P.B., International Committee on Allergic Diseases of Animals (ICADA) (2014). Validation of the canine atopic dermatitis extent and severity index (CADESI)-4, a simplified severity scale for assessing skin lesions of atopic dermatitis in dogs. Veterinary Dermatology 25, 77-e25.

Plant J.D., Gortel K., Kovalik M., Polissar N.L., Neradilek M.B. (2012). Development and validation of the canine atopic dermatitis lesion index, a scale for the rapid scoring of lesion severity in canine atopic dermatitis. Veterinary Dermatology 23, 215-e103.

Rees C.A., Bauer J.E., Burkholder W.J., Kennis R.A., Dunbar B.L., Bigley K.E. (2001). Effects of dietary flax seed and sunflower seed supplementation on normal canine serum polyunsaturated fatty acids and skin and hair coat condition scores. Veterinary Dermatology 12, 111-117.

Watson T.D.G. (1998). Diet and skin disease in dogs and cats. The Journal of Nutrition 128, 2783-2789.

Weese J.S. (2013). The canine and feline skin microbiome in health and disease. Veterinary Dermatology 24, 137145-e31.

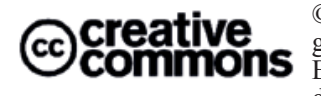

2021 by the authors. Licensee Vlaams Diergeneeskundig Tijdschrift, Ghent University, Belgium. This article is an open access article distributed under the terms and conditions of the Creative Commons Attribution (CC BY) license (http://creativecommons.org/licenses/by/4.0/). 